\title{
Prostate-specific antigen kinetics parameters are predictive of positron emission tomography features worsening in patients with biochemical relapse after prostate cancer treatment with radical intent: Results from a longitudinal cohort study
}

\author{
MAURO GACCI ${ }^{1}$, TOMMASO CAI ${ }^{2}$, GIAMPAOLO SIENA ${ }^{1}$, ANDREA MINERVINI ${ }^{1}$, \\ MOZHGAN FAYAZ TORSHZI ${ }^{3}$, MATTEO BARTOLINI ${ }^{3}$, GIANLUCA GIANNI', \\ CALOGERO SAIEVA* MAURO CEROTI" ${ }^{4}$, BEATRICE DETTI ${ }^{5}$, \\ LORENZO LIVI', ALBERTO PUPI ${ }^{3}$ \& MARCO CARINI \\ ${ }^{1}$ Department of Urology, ${ }^{3}$ Nuclear Biomolecular Medicine and, ${ }^{5}$ Department of Radiation Therapy, \\ University of Florence, Careggi Hospital, Florence, Italy, ${ }^{2}$ Deparment of Urology, Santa Chiara Regional Hospital, \\ Trento, Italy, and, and "Institute for Study and Prevention of Cancer (ISPO), Florence, Italy
}

\begin{abstract}
Objective. The aim of this study was to identify prostate-specific antigen (PSA) kinetics parameters predictive of $\left.{ }^{18} \mathrm{~F}\right]$ fluorocholine positron emission tomography/computed tomography $\left({ }^{18} \mathrm{FC} \mathrm{PET/CT}\right)$ features worsening in a cohort of patients with biochemical failure after prostate cancer treatment. Material and methods. This longitudinal cohort study comprised 103 consecutive patients. All patients underwent two ${ }^{18}$ FC PET/CT scans: one at baseline (PET1) and one after 6 months (PET2). Total PSA (IPSA), PSA velocity (VPSA), PSA doubling time (PSAdt), absolute variation in PSA values between PET2 and PET1 ( $\triangle P S A)$, and percentage variation in PSA between the two PSA measurements (PSA\%) were measured in each patient. Progression of disease on ${ }^{18} \mathrm{FC}$ PET/CT findings was compared with the PSA kinetics parameters. The major outcome measure was disease progression at PET2. Results. ${ }^{18} \mathrm{FC}$ PET/CT progression between PET1 and PET2 was reported in 64 patients $(62.1 \%)$, while in 39 cases it remained unvaried. The following PSA kinetic parameters correlated with worsened ${ }^{18} \mathrm{FC}$ PET/CT findings: $\triangle \mathrm{PSA}>5 \mathrm{ng} / \mathrm{ml}$ [odds ratio $(\mathrm{OR}=6.44,95 \%$ confidence interval $(\mathrm{Cl}) 1.04-39.6 ; p=0.04$ ), vPSA $>6 \mathrm{ng} / \mathrm{ml} / \mathrm{month}(\mathrm{OR}=5.2,95 \% \mathrm{CI} 0.9-29.8 ; p=0.05)$ and PSAdt $\angle 6$ months $(\mathrm{OR}=5.2,95 \% \mathrm{CI} 0.4-5.4 ; p=0.03)$. From receiver operating characteristics (ROC) analysis, the combination with the three PSA kinetics parameters for predicting worsened ${ }^{18} \mathrm{FC} \mathrm{PET} / \mathrm{CT}$ findings resulted in a sensitivity of $86 \%(95 \% \mathrm{CI} 77-92 \%)$ and specificity of $77 \%(95 \% \mathrm{CI} 65-85 \%)$. Conchusion. PSA kinetics is strictly related to ${ }^{18} \mathrm{FC}$ PET/CT findings. In patients with biochemical relapse, $\triangle \mathrm{PSA}>5 \mathrm{ng} / \mathrm{ml}$, PSAdt $<6$ months and vPSA $>6 \mathrm{ng} / \mathrm{ml} /$ month are highly predictive of ${ }^{18} \mathrm{FC}$ PET/CT features worsening, independently from the treatment received.
\end{abstract}

Key Words: biochemical failure, positron emission tomography, prostate neoplasm, prostate-specific antigen, ROC curve

\section{Introduction}

Biochemical failure after a treatment with radical intent for localized prostate cancer may occur in $15-77 \%$ of all patients during the first 5 years after treatment $[1,2]$. Prostate-specific antigen (PSA) relapse indicates evidence of illness and it is mandatory at this step to establish whether the disease is locally confined or systemic [3]. However, among the conventional imaging techniques, such as bone scan, computed tomography (CT) and magnetic resunance imaging (MRI), the most appropriate diagnostic

Correspondence: T. Cai, Department of Urology, Santa Chiara Regional Hospital, Largo Medaglie d'Oro 9, Trento, Italy. Tel: +390461903306 Fax: +390461903101 . E-mail: ktommy@libero.it 
investigation for asymptomatic men with biochemical failure is currently undefined $[4,5]$. In addition, conm ventional imaging is not useful when PSA is lower than $5 \mathrm{ng} / \mathrm{ml}$ and PSA doubling time greater than 10 months [6]. For this reason and because of the low accuracy shown by these techniques, the attention of several authors has been directed to other imaging techniques, and molecular imaging in particular [7]. $\left[{ }^{18} \mathrm{~F}\right]$ Fluorodeoxyglucose (FDG) has limited value in prostate cancer imaging owing its low cellular uptake but it may have a role in assessing treatment response to chemotherapy in hormone-resistant disease $[6,7]$. Radiopharmaceuticals targeting cell membrane lipid metabolism, such as $\left[{ }^{11} \mathrm{C}\right]$ choline, $\left[{ }^{18} \mathrm{~F}\right]$ choline or $\left[{ }^{1 /} \mathrm{C}\right]$ acetate, seem to be more promising for the detection of malignant prostate cancer cells, and all have proved to have a preferential uptake in prostate cancer cells, affected lymphatic ganglia and metastatic processes [8-10]. However, several authors have prom posed different PSA cut-off values and/or PSA prom gression (kinetics) for which prostate cancer patients should be referred to positron emission tomography (tomography PET)/CT, ranging from $1 \mathrm{ng} / \mathrm{ml}$ to $5 \mathrm{ng} /$ ml $[11,12]$. At present, the knowledge of the PSA level may not be sufficient to decide whether referral to $\left[{ }^{11} \mathrm{C} /{ }^{18} \mathrm{~F}\right]$ choline PET/CT is appropriate or not. Furthermore, PSA kinetic parameters predictive of tumour progression on $\left[^{11} \mathrm{C} /{ }^{18} \mathrm{~F}\right]$ choline PET/CT findings are not yet clearly defined.

The aim of this study was to analyse a cohort of patients with biochemical relapse after prostate cancer treatment with radical intent in order to identify PSA kinetics parameters predictive of worsened $\left[{ }^{18} \mathrm{~F}\right]$ choline PET $\left({ }^{18} \mathrm{FC}\right.$. PET/CT $)$ features.

\section{Material and methods}

Study design

To identify possible PSA kinetics parameters predictive of ${ }^{18} \mathrm{FC}$ PET/CT features worsening, all patients with biochemical relapse after radical treatment [radical prostatectomy (RRP) or definitive radiation therapy (RT)] between April 2006 and July 2008 were enrolled in this longitudinal cohort study. This study was planned as a longitudinal cohort study because it is a correlation research study that involves repeated observations of the same variables over long periods, in a specific group of people [13].

\section{Study population and schedule}

All patients with biochemical relapse within the study period were enrolled. All patients who met the eligim bility criteria underwent two consecutive ${ }^{18} \mathrm{FC} \mathrm{PET} /$
CT scans: one at baseline (PET1) and one at restaging after 6 months (PET2) (Figure 1). All PET images were interpreted by an independent masked committee who had no knowledge of the history of the patients (one nuclear medicine and one radiology specialist and one outside expert to resolve all cases of disagreement among readers). Progression of dis ease on ${ }^{18} \mathrm{FC}$ PET/CT findings was compared with the PSA kinetics parameters. Moreover, the ${ }^{18} \mathrm{FC}$ PET/CT findings were analysed to evaluate which PET findings were predictive of disease progression. All patients were stratified according to D'Amico risk criteria [14]

\section{Inclusion and exchasion criteria}

All patients with biochemical failure after treatment with radical intent, for whom information on all the main clinical and pathological features was available, were enrolled. Patients who had undergone RRP who showed positive margins or positive lymph nodes on pathological analysis were excluded, in order to enrol a homogeneous group to evaluate. Moreover, patients treated with neoadjuvant or adjuvant chemotherapy, or combined surgical and radiation therapy, were also excluded.

\section{Definition of biochemical relapse}

Biochemical falure was defined as at least two consecutive PSA measurements acquired 3 months apart above $0.2 \mathrm{ng} / \mathrm{ml}$ for patients undergoing RRP; and three consecutive values above $0.4 \mathrm{ng} / \mathrm{ml}$, after having reached the nadir, for those undergoing definitive RT $[3,15]$.

\section{Radical treatment schedule}

The RRP was performed as described by Walsh in 1998 [16]. RT is performed with a five-field intensitymodulated radiation therapy (IMRT) technique, delivered with a segmented multileaf collimator (MLC) technique also known as "step and shoot". In brief, pretreatment simulation CT was perfomed, with patient in the supine position, with an empty rectum and a full bladder. The treatment is usually delivered with an Elekta Synergy linear accelerator that is equipped with imaging tools, including threedimensional cone-beam imaging. Image control during the treatment consisted of a cone beam for the first 5 days of treatment and then weekly, after correction of the position based on the mean error. All patients were treated with 80 Gy in standard fractions (2 Gy/ day) $[17-19]$. 
Timing

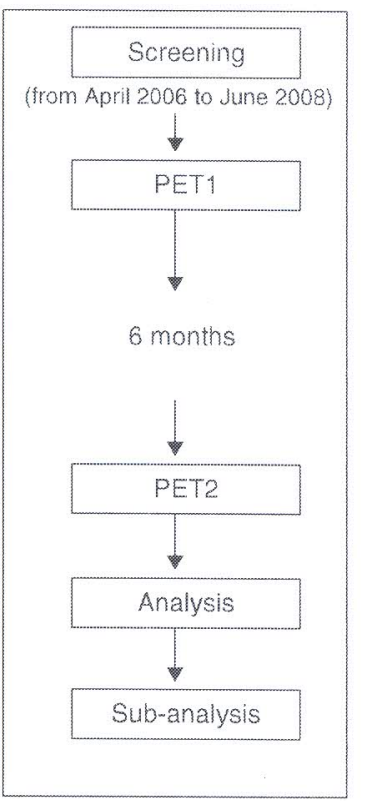

Patients

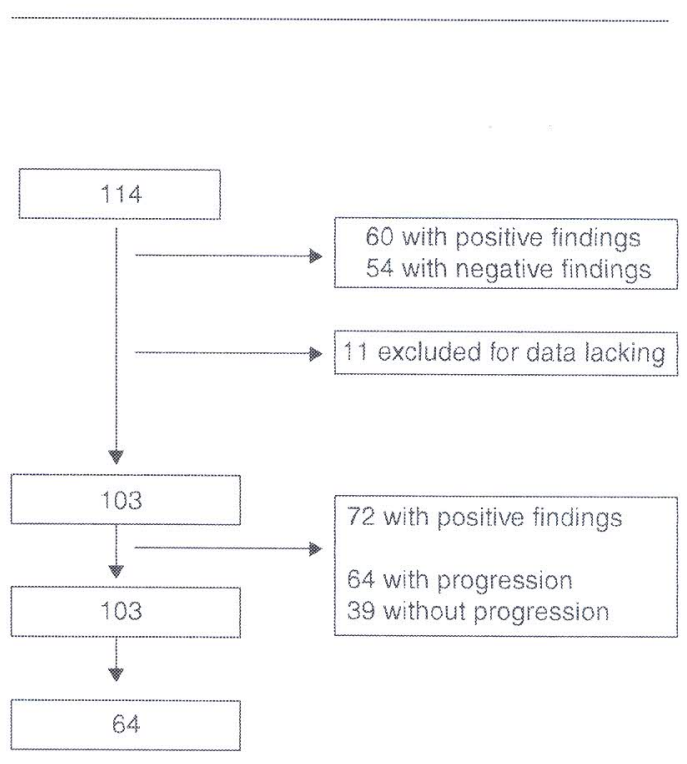

Figure 1. Study schedule flowchart and study design.

Determination of prostate-specific antigen and prostatespecific antigen kinetics

At least five PSA measurements were available from each patient: pretreatment PSA, two consecutive PSA measurements at biochemical failure, and one each at PET1 and PET2. The following PSA values were measured in all patients: total PSA (tPSA), PSA velocity (vPSA) according to the formula (PSA2 PSA1)/A time, PSA doubling time (PSAdt) according to the formula $\ln (2) \times \Delta$ time $/[\ln (\mathrm{PSA} 2)-\ln (\mathrm{PSA} 1)]$, absolute variation in PSA values between PET2 and PET1 (APSA) according to the formula PSA2 PSA1, and percentage variation in PSA values between PET2 and PET1 (PSA\%) according to the formula PSA2/PSA $1 \times 100$. All PSA kinetics parameters were calculated in accordance with D'Amico et al. [20] and international guidelines [3]. PSA values were obtained either at Careggi Hospital or at a laboratory local to the patient. All PSA measurements were taken at the same place for each patient.

\section{$\left.{ }^{18}{ }^{H}\right]$ Cholne positron emission tomography/computed tomography procedures and imaging analysis}

$\left[{ }^{18} \mathrm{~F}\right]$ Choline (ACOM, Macerata, Italy) (dose $4 \mathrm{MBq} /$ $\mathrm{kg}$ ) was injected in an antecubital vein with the patient positioned on the PET/CT bed (Philips GXLGemini GXL PET/CT; Philips Healthcare, Netherlands).
The protocol included an early dynamic scan of the pelvis ( 4 min postinjection) and a delayed whole-body scan (60 min postinjection). Images were reconstructed with a proprietary algorithm and visually examined. Where necessary, $\left[{ }^{18} \mathrm{~F}\right]$ choline lesion uptake was quantified by comparison with the uptake in surrounding soft tissues. ${ }^{18} \mathrm{FC} \mathrm{PET} / \mathrm{CT}$ findings predictive of disease progression were the presence of an increased number of pathological $\left[{ }^{18} \mathrm{~F}\right]$ choline uptake sites (NoPS) and increased uptake intensity (UPI) (Figure 2). In line with Wahl et al., a change of $20 \%$ in tumour UPI was considered clinically significant [21]. Patients with negative ${ }^{18} \mathrm{FC}$ PET/CT findings at PET1 but with positive findings at PET2 were considered to have disease progression. The independent masked committee evaluated the ${ }^{18} \mathrm{FC}$ PET/CT images in consensus using a dedicated software package (Syngo Leonardo; Siemens Medical Solutions, Erlangen, Germany). During folloxy-up, ${ }^{18} \mathrm{FC}$ PET/CT findings were verified as true positive by comparing the PET1 with the PET2 data, or if needed by high-dose CT, bone scintigraphy or MRI. Only true-positive findings on ${ }^{18} \mathrm{FC}$ PET/CT were included for PSA correlation.

\section{Statistical analysis}

Descriptive statistics involved non-parametric meam sures; all quantitative data are expressed as mean $\pm \mathrm{SD}$. Comparisons of continuous variables 

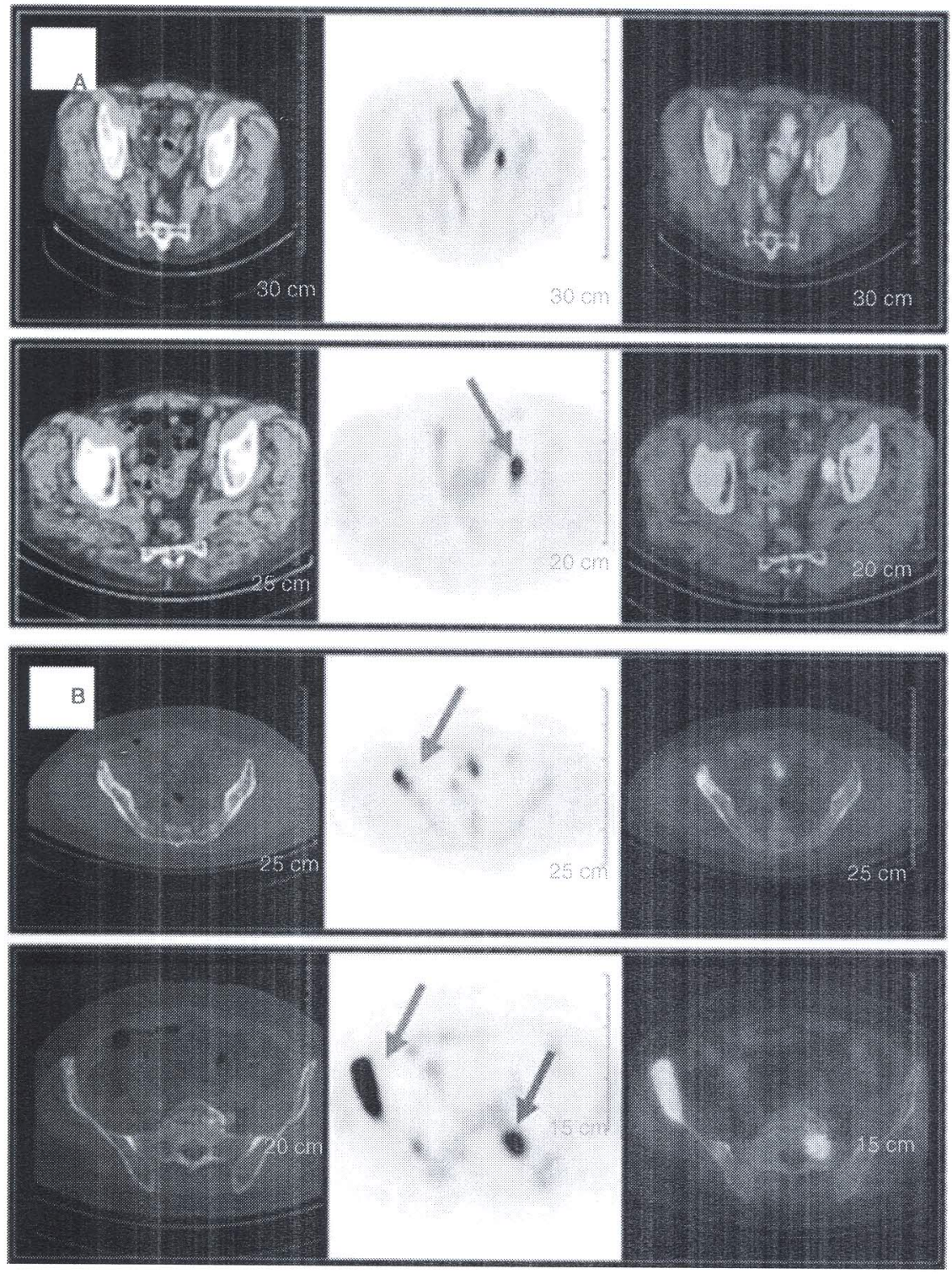

Figure 2. $\left[{ }^{16} \mathrm{~F}\right]$ Fluorocholine positron emission tomography/computed tomography $\left({ }^{18} \mathrm{FC} \mathrm{PET/CT}\right)$ findings: (A) increased uptake intensity; (B) increased number of pathological 18F-choline uptake sites.

between two groups were performed using the $t$ test. Comparisons of continuous variables were performed using one-way analysis of variance (ANOVA). The chisquared test was used for categorical variables. The $t$ test was used to evaluate the differences in PSA parameters between men presenting unvaried PET and those presenting worsened PET; appropriate non-parametric tests (chimsquared or Wilcoxon test) were used to assess the differences between men with an improvement in the number of lesions and those with an improvement number of lesions and UPI. The association between clinical, pathological and laboratory features and ${ }^{18} \mathrm{FC}$ PET/CT findings was assessed using univariate and multivariate analysis using the log-rank test (Mantel Cox) for multivariate analysis. The parameters considered for univariate and multivariate analysis were chosen in accordance with Giovacchini et al. [22] and are as follows: age, Gleason score at biopsy, PSA before radical treatment, clinical stage, type of radical treatment, pathological stage (for surgery only), Gleason score at surgery, time to PSA nadir, time to biochemical progression, UPSA at biochemical progression, tPSA, PSAdt, vPSA, $\triangle P S A$ and PSA\%. Furthermore, 
Table 1. Clinical and instrumental characteristics of all enrolled patients.

\begin{tabular}{|c|c|}
\hline Enrolled patients & 103 \\
\hline Age (years) & $64.8=6.5$ \\
\hline \multicolumn{2}{|l|}{ Glcason score (biopsy) } \\
\hline 6 & $23(22.4)$ \\
\hline $7(3+4)$ & $42(40.7)$ \\
\hline $7(4+3)$ & $33(32.1)$ \\
\hline 8 & $5(4.8)$ \\
\hline PSA pretreatment & $9.8=7.3$ \\
\hline \multicolumn{2}{|l|}{ Clinical TNM } \\
\hline CTINOMO & $12(11.6)$ \\
\hline CT2NOMO & $91(88.4)$ \\
\hline Comorbidity Charlson Index & $2.1=0.9$ \\
\hline \multicolumn{2}{|l|}{ Radical treatment and hormonal therapy } \\
\hline Radical prostatectomy & $83(80.5)$ \\
\hline With hormonal therapy & $15(18)$ \\
\hline Without hormonal therapy & $68(82)$ \\
\hline Radiation therapy & $20(19.5)$ \\
\hline With hormonal therapy & $18(90)$ \\
\hline Without hommonal therapy & $2(10)$ \\
\hline \multicolumn{2}{|l|}{ Pathological stage (surgery) } \\
\hline pT2a & $12(14.4)$ \\
\hline pT2b & $19(22.9)$ \\
\hline pT2c & $23(27.7)$ \\
\hline pT3a & $19(22.9)$ \\
\hline pT3b & $10(12.1)$ \\
\hline No & 103 \\
\hline $\mathrm{N})-2$ & - \\
\hline Positive margins & - \\
\hline \multicolumn{2}{|l|}{ Gleason scone (surgery) } \\
\hline 6 & $6(7.2)$ \\
\hline $7(3+4)$ & $34(40.9)$ \\
\hline $7(4+3)$ & $40(48.2)$ \\
\hline 8 & $3(3.7)$ \\
\hline Time to PSA nadir (months) & $6.9 \div 4.9$ \\
\hline Time to biochemical progression (months) & $20.1 \pm 11.3$ \\
\hline tPSA at biochemical progression & $0.9 \pm 0.4$ \\
\hline Interval: primary therapy to PET/CT I (months) & $19.8=9.7$ \\
\hline Interval: PET/CT 1 to PET/CT 2 (months) & $6.9 \pm 1.1$ \\
\hline
\end{tabular}

The table shows all patient anamnestic characteristics, clinical and laboratory data at the time of enrolment. Data are shown as mean $=S D$ or $n(\%)$.

PSA = prostate - specific antigen; $T N M=$ tumour, node, metastasis; tPSA = total PSA; PET = positron emission comography; $C T=$ computed tomography.

the receiver operating characteristics (ROC) analysis was generated by plotting sensitivity versus $1-$ specificity, with judgement of the optimal cut-off values for TPSA and PSA kinetics to predict worsened ${ }^{18} \mathrm{FC}$ PET/CT scan results [23]. All tests were two sided.
Statistical significance was taken at $p<0.05$. All statistical analyses were performed using the SAS program (version 9.1).

Written informed consent for the execution of the ${ }^{18} \mathrm{FC}$ PET/CT scan and the anonymous publication of disease-related information was signed by each patient. The study was conducted in line with good clinical practice guidelines and with the ethical principles laid down in the latest version of the Declaration of Helsinki.

\section{Results}

From April 2006 to July 2008, 114 patients met the criteria and 103 were finally enrolled into this longitudinal cohort study and followed for 6 months, after the first ${ }^{18} \mathrm{FC} \mathrm{PET/CT}$ time. Eleven patients were excluded owing to missing clinical or laboratory data (Figure 1). The patients' characteristics are summarized in Table $I$.

\section{[187Choline positron emission tomography/computed tomography and prostare-specific antigen results}

At PET1, 60 patients $(58.3 \%)$ showed positive find ings (45 RRP group and 15 RT group). On an anatomical basis, pathological uptake was observed in lymph nodes (19 patients, 31.7\%), in the prostatectomy bed ( 15 patients, $25 \%$ ) and in the skeleton (26 patients, 43.3\%). At PET2, 72 patients (69.9\%) (66 RRP and 16 RT group, respectively) had positive findings ( 26 lymph nodes, 24 prostatectomy bed and 22 in the skeleton). Overall, PET progression between PETI and PET2 was reported in 64 patients $(62.1 \%)$, while in 39 cases PET findings remained unvaried (Figure 1). According to the type of treatment, $45(54.2 \%)$ patients who had undergone RRP showed positive findings at PET1 and $66(79.5 \%)$ at PET2, while among all patients who had undergone RT, $15(75 \%)$ showed positive findings at PET1 and $16(80 \%)$ at PET2. Moreover, among all patients who had undergone RRP, $64(77.1 \%)$ showed prom gression of disease on ${ }^{18} \mathrm{FC}$ PET/CT findings, as did $11(55 \%)$ of those who had undergone RT. A comparison analysis according the type of treatment was not carried out, as this was not a study aim. Only the results are described here.

Correlation between positron emission tomography findings and prostate-specific antigen kinetics parameters

Table II shows all PSA kinetics parameters according to the PET changes between PET1 and PET2. ROC analysis identified the optimal threshold of $\triangle P S A$ for prediccion of PET features worsening as greater than 
Table 11. Prostatemspecific antigen (PSA) kinetics parameters according to positron emission tomography (PET) changes between PETl and PET2.

\begin{tabular}{|c|c|c|c|c|}
\hline & $\begin{array}{l}\text { All } \\
\text { patients }\end{array}$ & $\begin{array}{c}\text { Patients } \\
\text { with } \\
\text { progression }\end{array}$ & $\begin{array}{c}\text { Patients } \\
\text { whithout } \\
\text { progression }\end{array}$ & $p^{3}(\mathrm{~d} f ; i)$ \\
\hline $\begin{array}{l}\text { No. of patients } \\
\text { tPSA (ng/mI) }\end{array}$ & 103 & 64 & 39 & \\
\hline Mean & 0.9 & 1.0 & 0.9 & 0.14 \\
\hline Median & 0.8 & 0.9 & 0.8 & $(101 ; 1.4)$ \\
\hline $\mathrm{SD}$ & 0.4 & 0.6 & 0.2 & \\
\hline \multicolumn{5}{|l|}{$\begin{array}{l}\text { vPSA } \\
\text { (ng/ml/month) }\end{array}$} \\
\hline Mean & 4.8 & 6.4 & 4.1 & $<0.001$ \\
\hline Median & 6.3 & 6.3 & 3.9 & $(101 ; 12.0)$ \\
\hline SD & 1.2 & 0.9 & 1.0 & \\
\hline \multicolumn{5}{|l|}{$\begin{array}{l}\text { PSAdt } \\
\text { (months) }\end{array}$} \\
\hline Mean & 5.9 & 6.2 & 4.9 & $<0.001$ \\
\hline Median & 6.1 & 6.1 & 4.7 & $(101 ; 7.3)$ \\
\hline $\mathrm{SD}$ & 1.3 & 0.7 & 1.1 & \\
\hline \multicolumn{5}{|l|}{$\triangle P S A(n g / m l)$} \\
\hline Mean & 4.9 & 5.4 & 3.9 & $<0.001$ \\
\hline Median & 5.2 & 5.3 & 3.7 & $(101 ; 8.8)$ \\
\hline SD & 1.3 & 0.5 & 1.2 & \\
\hline \multicolumn{5}{|l|}{$\triangle P S A \%(\mathrm{ng} / \mathrm{ml})$} \\
\hline Mean & 9.8 & 10.7 & 9.9 & 0.32 \\
\hline Median & 9.9 & 10.5 & 9.6 & $(101 ; 0.9)$ \\
\hline $\mathrm{SD}$ & 3.2 & 3,4 & 4.8 & \\
\hline
\end{tabular}

${ }^{a} p$ Value calculated on the mean; df $=$ degrees of freedom; $t=i$ value tPSA = total PSA; $v$ PSA = PSA velocity; PSAdt = PSA doubling time; $\triangle P S A=$ change in PSA: $\mathrm{PSSA} \%=$ percentage variation in PSA between the two PSA measurements.

$5 \mathrm{ng} / \mathrm{ml}$, resulting in a sensitivity of $63 \%[95 \% \mathrm{con}$ fidence interval (CI) $58-68 \%$ and a specificity of $79 \%(95 \%$ CI $77-2 \%)$. An increase in PSA value (APSA) greater than $5 \mathrm{ng} / \mathrm{ml}$ at PET2 compared to PETI related to a six-fold higher risk of worsened PET findings lodds ratio $(O R)=6.44, \mathrm{CI} 1.04-39.6$; $p=0.04$. ROC analysis revealed that the optimal cutoff of VPSA for the prediction of PET features worsening was greater than $6 \mathrm{ng} / \mathrm{ml} / \mathrm{month}$, resulting in a sensitivity of $72 \%(95 \%$ CI $67-81 \%)$ and a specificity of $78 \%(95 \%$ CI $75-82 \%)$. Moreover, the ROC analysis yielded an optimal cut-off when the doubling time was less than 6 months (sensitivity $78 \%, 95 \% \mathrm{CI}$ $73-81 \%$; specificity $79 \%, 95 \%$ Cl $73-85 \%)$. There was also a significant risk of PET findings worsening in the case of vPSA greater than $6 \mathrm{ng} / \mathrm{ml} / \mathrm{month}$ and PSAdt less than 6 months, of five times $(O R=5.2, \mathrm{CI}$ $0.9-29.8 ; \mathrm{p}=0.05)$ and 10 times higher $(\mathrm{OR}=5.2, \mathrm{CI}$ $0.4-5.4 ; p=0.03)$, respectively. In multivariate analysis, $\triangle$ PSA greater than $5 \mathrm{ng} / \mathrm{ml}$, PSAdt less than 6 months and WPSA greater than $6 \mathrm{ng} / \mathrm{ml} / \mathrm{month}$
Table II. Univariate and multivariate analysis results of factors affecting worsening positron emission tomography (PET) features.

\begin{tabular}{|c|c|c|}
\hline Categories (variables) & $\begin{array}{l}\text { Univariate } \\
\text { analysis }(p)\end{array}$ & $\begin{array}{l}\text { Multivariate } \\
\text { analysis }(p)\end{array}$ \\
\hline Age & 0.11 & 0.45 \\
\hline PSA at diagnosis & 0.09 & 0.16 \\
\hline $\mathrm{GS}>0=7$ at biopsy & 0.12 & 0.07 \\
\hline Cinical stage & 0.54 & 0.23 \\
\hline Type of treatment & 0.40 & 0.51 \\
\hline Pathological stage ${ }^{a}$ & 0.36 & 0.27 \\
\hline GS $>0=7$ at biopsy" & 0.22 & 0.09 \\
\hline PSA nadir & 0.08 & 0.10 \\
\hline PSAO & 0.25 & 0.12 \\
\hline$\triangle P S A>5 \mathrm{ng} / \mathrm{ml}$ & 0.38 & 0.003 \\
\hline PSAdt $<6$ months & 0.08 & 0.04 \\
\hline vPSA $>6 \mathrm{ng} / \mathrm{ml} / \mathrm{month}$ & 0.45 & 0.02 \\
\hline Adiuvant hormonal therapy & 0.09 & 0.07 \\
\hline Charlson Index & 0.09 & 0.09 \\
\hline Time to biochemical progression & 0.33 & 0.41 \\
\hline tPSA at biochernical progression & 0.42 & 0.45 \\
\hline
\end{tabular}

Calculated among patients who had undergone surgical treatment. PSA $=$ prostate--specific antigen; GS = Gleason score; PSA $\%$ percentage variation in PSA between the two PSA measurem ments; $\triangle P S A=$ absolute variation in PSA values between the wo PSA measurements; PSAdt = PSA doubling time; vPSA = PSA velocity; $t P S A=$ total $P S A$

remained independently associated with PET features worsening $(p=0.003, p=0.041$ and $p=0.021$, respectively) (Table III). From ROC analysis, the combination of the three PSA kinetics parameters for predicting worsened PET findings resulted in a sensitivity of $86 \%(95 \%$ CI $77-92 \%)$ and a specificity of $77 \%(95 \%$ Cr $65-85 \%)$ (Figure 3$)$.

\section{Subanalysis in patients with $/^{18}$ F/choline positron emission tomography/computed tomography progression}

In one out of 64 patients an increase in UPI alone was recorded, while in 63 an increase in both NoPS and NoPS/UPI on PET2 findings was recorded. Of those, 13 out of 63 patients $(20.4 \%)$ showed exclusively an increase in the NoPS, whereas 50 out of $63(79.6 \%)$ showed an increase in both NoPS and UPI. Mean PSAdt was $0.4 \pm 2.4$ months and $3.9 \pm 8.8$ months for patients with NoPS/UPI increase and for patients with NoPS increase, respectively $(p=0.01)$. Mean $\triangle$ PSA was $-2.30 \pm 13 \mathrm{ng} / \mathrm{ml}$ and $14.7 \pm 32 \mathrm{ng} / \mathrm{ml}$ for patients with an increase in NoPS alone and patients with an increase in NoPS/UPI; respectively $(p=0.04)$. VPSA and PSA2/ PSA1 did not show any statistical difference between the two subgroups ( $p=0.11$ and 0.28 , respectively).

Using the D'Amico risk criteria, 22 patients were stratified as low risk (21.4\%), 74 as intermediate risk 


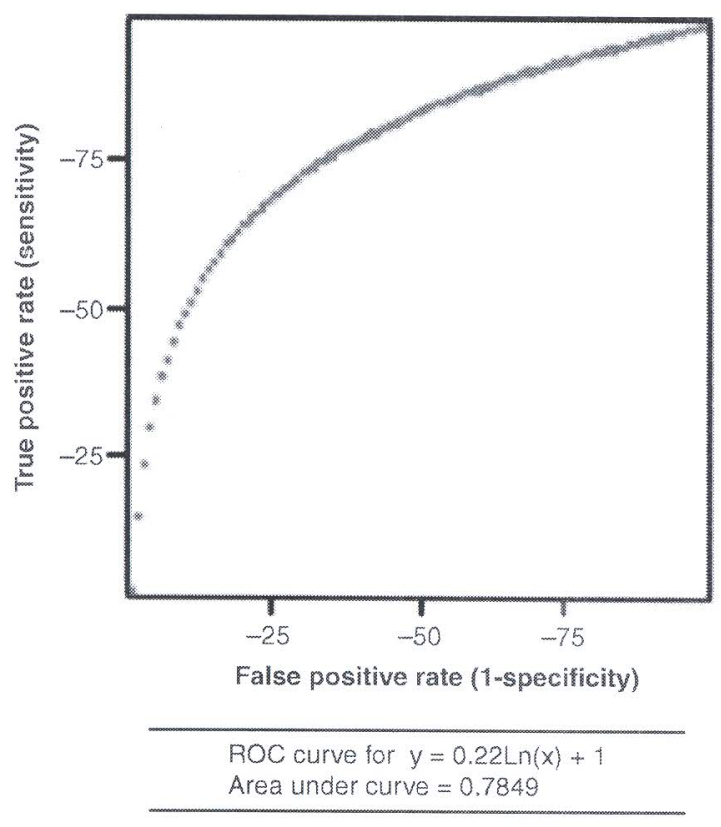

Figure 3. Receiver operating characteristics (ROC) curve

$(71.8 \%)$ and seven as high risk $(6.8 \%)$. However, no correlation was found between different risk groups and PET/CT findings at the PET1 or PET2 evaluation.

\section{Discussion}

Some authors have related the PSA kinetics param meters to poor clinical outcome in prostate cancer patients and argued that PSAdt could be used for stratification of patient treatment and prognosis [22]. Subsequently, the clinical implications of PSA kinetics parameters have become a major focus of research in prostate cancer. Moreover, the treatment of prostate cancer patients with biochemical relapse relies on the distinction between local and systemic disease and on pathological and clinical information, including PSA levels and PSA kinetics [24].

In the present cohort of patients, attention was focused on the PSA kinetics parameters for predicting the worsened ${ }^{18} \mathrm{FC}$ PET/CT findings in patients with biochemical failure after treatment with radical intent. In recent years, several authors have focused their research on this field of interest. Giovacchini et al. reported that high PSA and short PSAdt were significant predictors of positive PET [22]. Indeed, they report that the percentage of patients who displayed pathological $\left[{ }^{1 \mathrm{l}} \mathrm{C}\right] \mathrm{choline}$ uptake in the skeleton increased significantly from 3\% for PSAdt greater than 6 months to $52 \%$ for PSAdt less than 3 months [22]. Recently, Rybalov et al. found that tPSA and VPSA have significant effects on the detection rates of

$\left[^{11}\right.$ C]choline PET/CT in patients with biochemical progression after RRP or external beam radiotherapy, highlighting the role of PSA kinetics parameters in predicting positive results at PET evaluation [25].

The aim of the present study was to evaluate which PSA parameters are predictive of $\left[{ }^{18} \mathrm{~F}\right]$ choline PET (FC PET/CT) features worsening in a cohort of patients affected by biochemical failure after prostate cancer treatment with radical intent. In this cohort of patients it was found that PSA kinetics is strictly related to ${ }^{18} \mathrm{FC}$ PET/CT findings, and in patients with biochemical relapse, a $\triangle P S A$ greater than $5 \mathrm{ng} / \mathrm{ml}^{\text {, a }}$ PSAdr less than 6 months and a VPSA greater than $6 \mathrm{ng} / \mathrm{ml} /$ month are highly predictive of ${ }^{18} \mathrm{FC}$ PET/CT features worsening, independently from the treatment received. To the authors' knowledge, this longitudinal cohort study is the first to show that some PSA kinetics parameters are useful in predicting the ${ }^{18} \mathrm{FC}$ PET/CT features worsening in patients who have undergone surgery or radiation therapy. This aspect is extremely important to make the results clinically relevant. Patients who had undergone radical prostatectomy with lymph-node dissection and those who had undergone radiation therapy were analysed.

Graute et al, identifed the optimal IPSA threshold of $1.74 \mathrm{ng} / \mathrm{ml}$ for the presence of ${ }^{18} \mathrm{FC} \mathrm{PET} / \mathrm{CT}$ derectable lesions, in 82 consecutive patients with biochemical relapse after radical prostatectomy [11]. Although some authors have found that at biochemical relapse PET findings are related to tPSA at the time of scanning, in the present study population the IPSA was not predictive of PET features worsening at PET2 evaluation [11]. Even if the TPSA alone is a crucial indicator of disease progres sion, in this study population it was not able to predict the detectable modification of PET features, while other PSA parameters were more effective in predicting that result. "These results need to be confirmed by other experiences before entering daily clinical practice. Furthermore, as reported by several authors, patients with positive ${ }^{18} \mathrm{FC} \mathrm{PET/CT} \mathrm{had}$ shorter PSAdt and faster vPSA than patients with negative ${ }^{18} \mathrm{FC} \mathrm{PET} / \mathrm{CT}[26,27]$. Indeed, it was found that a PSAdt less than 6 months was associated with a 10-fold higher risk of worsened PET findings and a five-fold greater risk of faster vPSA (>6 ng/ml/month).

On the basis of the image patterns, a statistically significant difference was observed in terms of PSAdt for patients with NoPS/UPI increase and for those with NoPS increase alone. The significant relationship between PSAdt and the image pattern is highly indicative of how an increased. UPI associated with increased NoPS is more likely to happen in the case of more aggressive discases and has a higher accuracy than the increased NoPS alone. 
A couple of limitations of this study should be taken into account: the short follow-up period and the limited number of patients. However, the progression at the ${ }^{18} \mathrm{FC} \mathrm{PET/CT}$ was used as a surrogate of overall survival, which requires a shorter follow-up. The limited number of patients is due to the cost of the methods used. Moreover, the study enrolled the minimum number of patients needed to obtain statistically significant results.

In conclusion, in this study cohort of patients with biochemical recurrence of prostate cancer after radical treatment, $\triangle$ PSA greater than $5 \mathrm{ng} / \mathrm{ml}$, PSAdt less than 6 months and vPSA greater than $6 \mathrm{ng} / \mathrm{ml} / \mathrm{month}$ are predictive of ${ }^{18} \mathrm{FC}$ PET/CT features worsening. This implies potentially important clinical consequences because in those patients with $\triangle \mathrm{PSA}$ greater than $5 \mathrm{ng} / \mathrm{ml}$, PSAdt less than 6 months and vPSA greater than $6 \mathrm{ng} / \mathrm{ml} / \mathrm{month}$, the therapy could be individualized owing to the high risk of ${ }^{18} \mathrm{FC} \mathrm{PET} /$ CT features worsening and disease progression.

\section{Acknowledgement}

We are grateful to Professor John Denton for manuscript language revision.

Declaration of interest: The authors have declared that no competing interest exists. There is no funding to declare and there are no financial disclosures from any of the authors.

\section{References}

11) Dillioglugil O, Leibman BD, Kattan MW, Seale-Yawkins C, Wheeler TM, Scardino PT. Hazard rates for prugression after radical prostatectomy for clinically localized prostate cancer. Urology 1997;50:93-9.

[2] Pound CR, Partin AW, Eisenberger MA, Chan DW, Pearson JD, Walsh PC. Natural history of progression after PSA elevation following radical prostatectomy. JAMA 1999; $281: 1591$.

[3] Heidenreich A, Bellmunt ], Bolla $M$, Joniau $S$, Mason $M$, MatveevV. European Association of Urology (GAU) guidelines on prostate cancer. Part 1: screening, diagnosis, and treament of clinically localised disease. Eur Urol $2011,59: 61-7$.

[4] Mohile SG, Petrylak DP. Management of asymptomatic rist in prostatic-specific antigen in patients with prostate cancer. Curr Oncol Rep 2006;8:213-20.

[5] Moul JW. Prostate specific antigen only progression of prostate cancer. J Urol 2000;163:1632-42.

[6] Choueir TK, Dreicer R, Paciorek A, Carroll PR, Konety B. A model that predicts the probability of positive imaging in prostate cancer cases with biochemical failure after initial definitive local therapy, J Urol 2008; 179:906-10.

[7] Picchio $M$, Castellucci $P$. Clinical indications of $C$-choline PET/CT in prostate cancer parients with biochemical relapse. Theranostics $2012 ; 2,313-17$.
[8] Kotzerke ], Prang J, Neumaier B, Volkmer B, Guhlmann A Kleinschmidt K, et al. Experience with carbon-11 choline positron emission tomography in prostate carcinoma. Eur J Nucl Med 2000;27:1415-19.

[9] De Jong I], Pruim J, Elsinga PH, Vaalburg W, Mensink Hy. Visualizarion of prostate cancer with $11 \mathrm{C}$-choline positron emission tomography. Eur Urol 2002; 42:18 23.

[10] Vees H, Buchegger $\mathrm{F}$, Abrecht $\mathrm{S}$, Khan $H$, Husarik D, Zaidi $\mathrm{H}$, et al $18 \mathrm{~F}$-choline and/or (11) C-acetate positron emission tomography: detection of residual or progressive subclinical disease at very low prostate-specific antigen values (< I ng/mL) after radical prostatectomy. BIU Int 2007;99: $1415-20$

[11] Graute $V$, Jansen $N$, Ubleis $C$, Seiz $M$, Hartenbach $M$, Scherr MK, et al. Relationship between PSA kinetics and [(18)F] fluorocholine PET/CT detection rates of recurrence in patients with prostate cancer after total prostatectomy. Eur I Nucl Med Mol lmaging 2012;39:271 82

[12] Krause B], Souvatzoglou $M$, Tuncel $M$, Hemmann $K$, Buck AK, Praus C, et al. The detection rate of [(11)C] choline-PET/CT depends on the serum PSAmvalue in patients with biochemical recurrence of prostate cancer. Eur I Nucl Med Mol Imaging 2008;35:18-23.

[13] Porta M. editor. A dictionary of epidemiology. 5th ed. New York: Oxford University Press; 2008.

[14] D'Anico AV, Whitrington R, Malkowicz SB, Fondurulia I, Chen MH, Kaplan I, et al. Pretreatment nomogram for prostate-specific antigen recutrence after radical prostatectomy or external-beam radiation therapy for clinically localized prostate cancer. J Clin Oncol 1999:17:168-72.

[15] Ruach M III, Hanks G, Thames $H$ Ir, Schelhammer $P$, Shipley WU, Sokol GH, et al. Defining biochemical failure following radiotherapy with or without hormonal therapy in men with clinically localized prostate cancer: recommendations of the RTOGmASTRO Phownix Consensus Conference. Int J Radiat Oncol Biol Phys 2006;65:965-74.

[16] Walsh PC. Anatomic radical prostatectomy: evolution of the surgical technique. J Urol $1998 ; 160: 2418-24$.

[17] Zelefsky MJ, Fuks Z, Hunt M, lee HJ, Lombardi D, $\operatorname{ling} \mathrm{CC}_{\text {, }}$ et al. High dose radiation delivered by intensity modulated conformal radiotherapy improves the outcome of localized prostate cancer. J Urol 2001; 166:876-81; cratum 166:1839.

[18] Gade TN, Guo L, Forde [, Vaux K, Vass J, Hunt P, et al. Image-guided dosemescalated intensity-modulated radiation therapy for prostate cancer: treating to doses beyond 78 Gy. BJU Int 2012;109:1655 60

[19] Payley A, Rosewall $T$, Craig $T$, Bristow R, Chung $P$, Gospodarowicz $M$, et al. Clinical application of high-dose, image-guided intensity-modulated radiotherapy in bighmrisk prostate cancer. Int I Radiat Oncol Biol Phys 2010;77: $477-83$

[20] D'Amico AV, Moul NW, Camoll PR, Sun L, lubeck D, Chen MH. Surrogate end point for prostate cancermspecific morality after radical prostatectomy or radiation therapy. J Natl Cancer Inst 2003;95:1376-83.

[21] Wah RL, Jacene $\mathrm{H}$, Kasamon Y, Lodge MA. From RECIST to PERCIST: evolving considerations for PET response criteria in solid tumors. I Nucl Med 2009;50:122-50S.

[22] Giovacchini G, Picchio M, Parra RG, Briganti A, Gianolli L Montorsi $F$, et al. Brostatemspectic antigen velocity versus prostate-specific antigen doubling time for prediction of ${ }^{11} \mathrm{C}$ choline PET/CT in prostate cancer patients with biochemical failure after radical prostatectomy. Clin Nucl Med 2012;37: $325-31$ 
[23] Beam CA. Analysis of clustered data in receiver operating characteristic studies. Stat Methods Med Res 1998;7: $324-36$.

[24] Darwish OM, Raj GV. Management of biochemical recurrence after primary localized therapy for prostate cancer. Front Oncol 2012;2:48.

[25] Rybalov M, Breeuwsma AJ, Leliveld AM, Pruim J Dierckx RA, de Jong IJ. Impact of total PSA, PSA doubling time and PSA velocity on detection rates of (11)C-choline positron emission tomography in recurrent prostate cancer. World J Urol 2013;31:319-23.
[26] Castellucei P, Fuccio C, Namni C, Santi I, Rizzello A, Indi $F$, et al. Influence of trigger PSA and PSA kinetics on "C-choline PET/CT detection rate in patients with biochemical relapse after radical prostatectomy. I Nucl Med 2009;50:1394-400

[27] Pichio M, Spinapolice EG, Fallanca F, Crivellaro C, Giovacchini G, Gianolli $L$, et al. [11C/Choline PET/CT detection of bone metastases in patients with PSA progression after primary treatment for prostate cancer: comparison with bone scintigraphy. Eur J Nud Med Mol Imaging 2012;39:13-26 